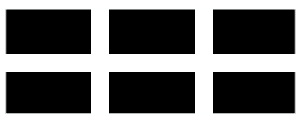

THE WILLIAM DAVIDSON INSTITUTE AT THE UNIVERSITY OF MICHIGAN BUSINESS SCHOOL

\title{
Human Capital, Growth and Inequality in Transition Economies
}

\author{
By: Michael Spagat
}

William Davidson Working Paper Number 499

July 2002 
Forthcoming in:

Nauro Campos and Jan Fidrmuc (eds.), "Political Economy of Transition and Development: Institutions, Politics and Policies." ZEI Studies in European Economics and Law, Kluwer Academic Publishers, Boston/Dordrecht/London.

Human Capital, Growth and Inequality in Transition Economies

By

Michael Spagat*

CEPR, The William Davidson Institute and

Department of Economics

Royal Holloway, University of London

Egham, Surrey, TW20 0EX, UK

M.Spagat@rhul.ac.uk

July, 2002

\begin{abstract}
Transition economies have an initial condition of high human capital relative to living standards. I explore the possible implications of this key fact by surveying and adapting literature on growth and inequality. I focus especially on the long run and policy options.
\end{abstract}

Key Words: Transition economies, human capital, growth, inequality, liquidity constraints, educational reform, long run

JEL Numbers: P2, O15, I2

\footnotetext{
*This paper grew out of lectures I delivered at the ZEI-CEPR Conference "Labour Markets, Work and Welfare During The Transition and Integration Process”, Riga, Latvia, March 2001. I am grateful to Michael Kaganovich for many useful discussions on the subject of this paper.
} 


\section{INTRODUCTION}

Economies undergoing transition from central command to markets represent major challenges to economic theory. One such challenge is to the conventional wisdom of economic growth of recent decades: the role in productivity growth that economic theory as well as empirical literature attributes to the stock of an economy's human capital. The model of economic growth presented in Lucas (1988) "On the Mechanics of Economic Development", where education is introduced as a major factor of sustainable growth, has become a standard approach to modeling growth. The puzzling feature of most transition economies, according to the premise of the "new growth theory", is that educational achievements in them are completely out of proportion to their per capita GDPs. Namely, standard measures of educational attainment are as high or even higher than in the world's richest countries yet the typical transition economy has a per capita GDP similar to that of a middle income developing country. Therefore, from the growth theory perspective, the economies in this group are in acute imbalance with regard to utilization of their human capital resources; hence one should expect the transition process to rectify this.

The empirical growth literature [e.g., Barro and Sala-i-Martin (1995) and Krueger and Lindahl (2001)] suggests that education is indeed an important factor of economic growth. On this basis one might expect that transition economies should be rapidly improving their performance, particularly in modern hi-tech sectors of the economy, and thus their productivity levels should be on their way to catching up with the trend corresponding to their human capital levels. The evidence so far suggests, however, that this vision is not supported by the experience of many transition economies, and certainly 
of most of the former Soviet successor states. Below I will present models that can display the reverse pattern: rather than an economy's productivity and living standards growing to match the high levels of its human capital indicators, it is the human capital that may deteriorate, in a lifetime of one generation, to match the third world levels of their living standards. Thus I argue that transition economies posses not only a potential for rapid growth but also a possibility for further deterioration, both in terms of productivity and human capital. I then consider some public policy options that could sustain high levels of educational attainment and facilitate productive utilization of human capital in transition economies.

There is a substantial body of recent literature documenting the superior educational attainment in most transition economies, as well as the current state of their educational sectors. Gros and Suhrcke (2000) systematically study education levels in transition countries using cross-section regressions on 148 countries and find that transition countries have much higher secondary and tertiary enrollment rates than their per capita GDP would predict. This general idea of a positive educational legacy of communism is confirmed in other studies including Micklewright (1999), UNICEF (2000) and UNICEF (2001) that also show that, after some initial dips, tertiary enrollments have tended to rise above pre-transition levels. These works do not, however, paint a universally rosy picture, emphasizing substantial disparities in access to education, based on family background, urban/rural location, ethnicity and financial resources. They also document substantial deterioration in educational provision quantified by decreased public expenditure and declining secondary school and preschool enrollments. These problems are especially sharp in the Caucasus and Central 
Asia but they affect all but perhaps the most successful Central European transition economies.

It is possible that declining enrollments are due to a failure of education to yield economic returns. In fact, Micklewright (1999), UNICEF (2000) and UNICEF (2001) all document particularly sharp drops in enrollment in vocational secondary schools which, in many cases, have surely been rendered obsolete in the new economic environment. However, Münich, Svejnar, and Terrell (1999) show that the transition from communism has brought a significant increase in the returns to human capital in the Czech Republic. It also summarizes most of the earlier empirical work for a variety of transition countries that tends to draw similar conclusions. Therefore, there must be some other factors driving declining enrollments, with family-level financial constraints being a likely candidate.

The literature offering a theoretical analysis of dynamics of human capital in transition economies and putting it into the mainstream growth theory perspective, however, has been so far quite limited. Spagat (1995) and Overland and Spagat (1996) study human capital investment in the transition economy environment as a matter of a government's optimal investment policy. These works stress the notion that, while human capital can only be built up slowly over the long term, it can deteriorate rapidly if basic maintenance investment is neglected. Thus, if government is short sighted and human capital investment is temporarily postponed, its decline can quickly take on an irreversible character.

Alexeev and Kaganovich (1998) (AK) analyze career dynamics of highly educated professionals at the initial stages of transition. Their model provides an 
explanation of the following phenomenon that characterized Russia's initial transition experience: it has been observed that the first crop of "nouveau riche" came out of the ranks of educated professionals who were less successful in their pre-transition careers and chose to abandon them at the first sign of looming reforms. According to AK's model, the most intellectually able individuals, the "good guys", had stronger incentives to exert high educational effort and hence had more successful professional careers (such as industrial engineering and science) prior to the start of reforms. They demonstrate that uncertainty over whether or not a major reform will be implemented can lead the "good guys", i.e., the more able people, to prepare relatively little for the possible change compared to less able people. This is because the good guys had higher opportunity cost of placing bets on reforms taking place. If reform is actually implemented, the good guys "finish last", compared to their formerly less successful counterparts, due to their failure to make an early market oriented career switch. One notable implication of this phenomenon, according to AK's model, is that resource and income distribution at the early stage of transition exhibits a significant mismatch with the distribution of human capital, at least, as far as the first generation of transition contemporaries is concerned. Fan, Overland and Spagat (1999) (FOS) has a strong connection with AK's conclusion. They argue that educational restructuring should have high priority early in Russia's transition process, emphasizing the potential for loss of human capital without such a policy. Like AK, FOS focus on individual-level human capital investment decisions, but they take the analysis one generation further. They stress the dependence of children's human capital acquisition decisions on the human capital of their parents (this empirically based fact is a standard premise of most models of education in the "new 
growth theory" literature). This fact, combined with the phenomenon, analyzed in AK, that many highly educated parents of the first transition generation fall behind in terms of incomes, leads FOS to demonstrate a potential failure of a transition economy to ensure intergenerational transmission of it initially high level of human capital. FOS also show how delaying educational reform can exacerbate economic inequality.

Spagat (2002) also models transition economies as having an initial condition of high human capital relative to GDP per capita, developing a framework in which this starting point can translate into two qualitatively distinct equilibria for the economy. At a good equilibrium a large number of children of well-educated parents take advantage of their family backgrounds and invest substantially in their own human capital. At a bad equilibrium, past educational achievements are wasted as children fail to build upon their parents' achievements (this analysis builds on the "poverty trap" models of development literature and adapts them to the transition policy dilemmas). I argued that this sort of multiple equilibria situation provides a basis for distinguishing development economics from transition economics. In particular, without a starting point based on high human capital an economy can only develop slowly and painfully. On the other hand, the high human capital starting point of transition economies creates a possibility, but not a certainty, of rapid economic development. Spagat (2001) also suggests that transition economies might be separating into two groups: a successful one in which human capital and living standards are rising and an unsuccessful group that is converging with the developing world. ${ }^{1}$

\footnotetext{
${ }^{1}$ There is some support for this idea in a recent EBRD report. Based on a survey of foreign investors and domestic enterprises it concludes that: “...firms in transition economies lag behind advanced industrialized countries in terms of the quality of their workforce. Such quality gaps are larger in the CIS than in CEE. This finding qualifies the view that the region has abundant human capital resources, despite considerable
} 
In this survey paper I will present various models from the large theoretical literature on human capital and growth with the goal of extracting useful lessons for transition economies. Sections three and four emphasize liquidity constraints and are based on models developed without reference to transition economies. Nevertheless, I believe the frameworks are quite illuminating for the transition context so I work through their possible implications for this case. Sections four and five focus on intergenerational externalities and are based on models I developed specifically for transition economies. I conclude in section six. Throughout the paper I consider possible policy interventions.

\section{LIQUIDITY CONSTRAINTS}

Consider a very simple model linking income distribution, liquidity constraints and human capital investment along the lines of Banerjee and Newman (1991) and Galor and Zeira (1993). The basic idea here is that inequality is bad for long-run growth. ${ }^{2}$ There is empirical evidence for this relationship (Perotti, 1996 and Benabou ,1996) although it has been questioned (Deininger and Squire, 1998).

Time is counted off at discrete intervals, $t=0,1,2, \ldots$. There are two sectors, a "skilled" sector and an "unskilled" sector. In every period the skilled wage is $w$ and the unskilled wage is 1 .

There is an overlapping generations structure with $N$ dynasties of agents indexed by $i$. Each agent lives two periods. Each family has one parent and one child alive at any point in time. As a matter of convention adults at time $t$ are called generation $t$.

achievements in formal education. Moreover, the lack of restructuring in the less reformed economies of the region means that many skilled workers are performing jobs that do not reflect their levels of education. Over time, there will be a continuing loss of skills, leading to an even greater gap in quality." (EBRD, 2000, p. iii of executive summary. Micklewright (1999) also provides some supporting evidence. 
Children either work and earn 1 or invest in human capital and pay $d>0$. Adults who did not invest in human capital earn an additional 1 while those who did invest in human capital earn $w$. I assume that $w-d>2$ so every agent wants to invest in human capital if possible.

Every agent has the same utility function $U(c, b)=\ln (c)+a \ln (b)$ where $a>0$ is a constant, $c$ is consumption and $b$ is a bequest that goes to the agent's child. Agent $i$ at time $t$ maximizes utility subject to the budget constraint:

$$
c_{i t}+b_{i t}= \begin{cases}w-d+b_{i, t-1} & \text { if skilled } \\ 2+b_{i, t-1} & \text { if unskilled }\end{cases}
$$

where subscript it refers to individual $i$ of generation $t$. The solution is:

$$
\begin{array}{ll}
b_{i, t}^{s}=\frac{a\left(w-d+b_{i, t-1}\right)}{1+a} & b_{i, t}^{u}=\frac{a\left(2+b_{i, t-1}\right)}{1+a} \\
c_{i, t}^{s}=\frac{w-d+b_{i, t-1}}{1+a} & c_{i, t}^{u}=\frac{2+b_{i, t-1}}{1+a}
\end{array}
$$

with $s$ and $u$ superscripts indicating skilled and unskilled agents respectively.

Individual $i$ of generation $t$ becomes skilled if and only if $b_{i, t-1} \geq d$. Suppose $2 a<d<\frac{a w}{1+a}$. Then the system converges to a situation where there are two types of dynasties: skilled and unskilled. Skilled individuals bequeath to their children $a(w-d)$, which is sufficient to allow the latter to invest in human capital. Unskilled individuals bequeath $2 a$ which is not sufficient to allow their offspring to invest.

\footnotetext{
${ }^{2}$ In the model inequality will be bad for output but I could reformulate the analysis in terms of growth rates.
} 
This very simple model turns out to provide a very rich basis for discussion. First, note that any dynasty that begins with a bequest below $d$ will remain unskilled forever. Therefore long-run output and welfare depends on the initial distribution of income. The relationship between inequality and output is complex. In a poor economy skewness is good for output because it leaves lots of agents with bequests above $d$. In a rich economy equality is helpful for getting lots of people above $d$.

Second, education subsidies financed with a tax on the rich can be beneficial for long-run output, although they will not necessarily be Pareto-improving. If, for example, adults are taxed with the proceeds transferred to children to overcome liquidity constraints for education, then there will be no way to compensate these adults from within the economic system. A possible alternative is to tax children with bequests above $d$ to bring other children with bequests below $d$ up to this threshold. The richer children could be fully compensated when they are adults. A problem with this approach is that it could distort the bequest motives of adults if they do not place full trust in compensation that is promised one generation in the future. Another interesting possibility is to use international borrowing to overcome liquidity constraints. In principle, such a scheme can be organized through an international organization such as the World Bank. The idea would be that money in the present would be used to finance educational investment with the money being repaid after the beneficiaries of the scheme were enjoying the enhanced earning potential that it has unlocked.

There are further interesting financing possibilities if there is an externality according to which the skill premium responds positively to the fraction of skilled workers in the population. For example, suppose the skilled wage in period $t$ is 
$w+\frac{k N_{t}^{s}}{N}$ and the unskilled wage is $1+\frac{k N_{t}^{s}}{N}$ where $k$ is a constant and $N_{t}^{s}$ is the number of skilled workers at time $t$. Such as externality introduces a further motivation for people above $d$ to be willing to pay taxes to allow other people to invest in their own human capital development.

Third, there are reasons for believing that early intervention will work much better than late intervention because subsidies will have to be larger once families have been unskilled for a long time than they would have to be before the class structure has fully hardened. In the initial period there may be many individuals with bequests just below $d$. If these individuals are denied access to educational investment then their descendents will have bequests farther from $d$ than they themselves were.

\section{EDUCATIONAL EXTERNALITIES}

I now take a closer look at the problem of financing human capital investment in the presence of externalities. I develop the model further based on Drazen (2000)'s version of Perotti (1993). I will drop time subscripts because I will focus on the situation at a single point in time. With this analysis in hand we could easily trace out full dynamics if we wished to do so.

There are three groups, High, Middle and Low of sizes $N^{H}, N^{M}$ and $N^{L}$ respectively where no group has more than half of the population. The income of each group is denoted $b^{H}, b^{M}$ and $b^{L}$ respectively where $b^{H}>d>b^{L}$ and $b^{M}$ is near the average income level $\bar{b} \equiv \frac{N^{H} b^{H}+N^{M} b^{M}+N^{L} b^{L}}{N}$ in a sense to be explained later. 
Income is taxed at a flat rate $\tau$ and revenue is redistributed to everyone in equal shares. This means that after-tax-and-redistribution income for each type is given by $I^{i} \equiv(1-\tau) b^{i}+\tau \bar{b}$ for $i=H, M, L$ and type $i$ invests in human capital if and only if $b^{i} \geq \frac{d-\tau \bar{b}}{1-\tau}$. This means that there is a critical tax rate $\tau^{i}=\frac{d-b^{i}}{\bar{b}-b^{i}}$, which determines whether or not high and low types invest. For high types $\tau^{i}$ is the maximum rate consistent with human capital investment. For low types $\tilde{\tau^{i}}$ is the minimum rate consistent with human capital investment.

The meaning of the assumption that $b^{M}$ is "near" the average income level $\bar{b}$ is that the tax rate does not affect the investment decision of the middle group. Specifically, I require that $b^{M}$ and $\bar{b}$ are on the same side of $d$. This is an assumption I will drop in later models.

Without an externality the most preferred tax rate for each group is zero for any group with income above the mean and one for any group with income above the mean. Now consider the effect of the same type of externality as was introduced in the previous section, namely, the skilled wage in period $t$ is $w+\frac{k N_{t}^{s}}{N}$ and the unskilled wage is $1+\frac{k N_{t}^{s}}{N}$ where $k$ is a constant and $N_{t}^{s}$ is the number of skilled workers at time $t$. Now most preferred tax rates will turn on whether or not $\bar{b}$ is greater than or less than $d$, i.e., on whether the economy is rich or poor. The basic idea is that in a rich economy high taxes are good for growth because if they are high enough then even Low agents can invest in human capital. If the externality is sufficiently strong a majority of the 
population will vote for high taxes even if Middle agents have above-average income.

On the other hand, in a poor economy low taxes are good for growth because taxes must to low if any agent, in particular High agents, is to invest in human capital. If the externality is strong enough low taxes can win even if the middle class has below average income.

More formally, define a Rich Economy by the property that high-income and middle-income agents will invest at any tax rate. Then at the tax rate $\tau^{L}=\frac{d-b^{L}}{\bar{b}-b^{L}}$ the poor also invest. High-income agents compare $\tau=0$ with $\tau=\tau^{\tilde{L}}$, preferring the former if $w+k+\left(1-\tau^{\tilde{L}}\right) b^{H}+\tau^{L} \bar{b}>w+k \frac{N^{H}+N^{M}}{N}+b^{H}$ and the latter otherwise. Lowincome agents prefer $\tau=1$. If $b^{M}<\bar{b}$ then middle-income agents agree with the poor on $\tau=1$. If $b^{M}<\bar{b}$ then middle-income agents prefer $\tau=0$ if $w+k \frac{N^{H}+N^{M}}{N}+b^{M}>w+k\left(1-\tau^{\tilde{L}}\right) b^{M}+\tau^{L} \bar{b}$ and $\tau=\tau^{\tilde{L}}$ otherwise.

Next consider the case of a poor economy defined by the property that the only agents who can possibly invest are high-income agents and they will only do so if taxes are sufficiently low. Then the most preferred tax rate for high-income agents is $\tau=0$. Low-income agents prefer $\tau=1$ if $w+\bar{b}>w+k \frac{N^{H}}{N}+\left(1-\tau^{\tilde{H}}\right) b^{L}+\tau^{\tilde{H}} \bar{b}$ and $\tau^{\tilde{H}}=\frac{d-b^{H}}{\bar{b}-b^{H}}$ otherwise. If $b^{M}<\bar{b}$ then middle-income agents prefer $\tau=1$ if $w+\bar{b}>w+k \frac{N^{H}}{N}+\left(1-\tau^{\tilde{H}}\right) b^{M}+\tau^{\tilde{H}} \bar{b}$ and $\tau^{\tilde{H}}=\frac{d-b^{H}}{\bar{b}-b^{H}}$ otherwise. If $b^{M}>\bar{b}$ then 
middle-income agents compare prefer $\tau=1$ if $w+b^{M}>w+k \frac{N^{H}}{N}+\left(1-\tau^{\tilde{H}}\right) b^{M}+\tau^{\tilde{H}} \bar{b}$ and $\tau^{\tilde{H}}=\frac{d-b^{H}}{\bar{b}-b^{H}}$ otherwise.

One can argue that some transition economies can be captured in this framework as poor with high $k$. The idea behind high $k$ is that there is major work to be done in building the institutions of a market economy. Since there are working models to learn from plus western cooperation, it is possible to build these institutions, and increase productivity, very quickly. There are also great opportunities for technological catch-up and even the possibility of leapfrogging over technologies that are entrenched in the West. But human capital is vital for this process and the more human capital that is available the faster will be the catch-up, institutional and technological. This suggest a possible scenario in which middle income people, and possibly low-income people as well, might cooperate by voting for low taxes to allow high-income people to invest in their own human capital. High $k$ means a large externality, which means that everyone benefits strongly from this investment.

Returning to the dynamic view one can envision the scenario continuing in the next generation with significantly higher taxes and widespread access to human capital investment. Thus, I arrive at a possible policy of elitism in the first generation and widespread access in the second generation. My opinion is that while I think this approach is worth serious consideration I am not inclined to support it. I believe the above view neglects a crucial starting condition of the transition, namely, that although transition economies tend to be poor they generally have achieved high educational 
standards. I next turn to the question of how to take advantage of the positive legacy of high educational standards and the danger it will be squandered.

\section{INTERGENERATIONAL EXTERNATILITIES ${ }^{3}$}

I now drop the financing constraint for human capital investment, i.e., set $d=0$. I retain our basic wage equation structure. In period $t$ the skilled wage for adults is $w+\frac{k^{s} N_{t}^{s}}{N}$ and the unskilled wage for adults is $1+\frac{k^{u} N_{t}^{s}}{N}$ where $k$ is a constant and $N^{s}$ is the number of skilled workers and $w>2$. Young people are either working for a wage of one or investing in human capital and earning zero. The main difference from what I had before is that now I allow the strength of the human capital externality to vary across sectors.

I impose the following assumptions: $w>2$ and $w k^{u}<2 k^{s}$. These assumptions ensure that skilled wages are always higher than unskilled wages and that the skill premium, i.e., the ratio of skilled to unskilled wages, is increasing in the number of educated people. This idea of complementarity between skilled workers seems particularly plausible in the transition economy case in which institution building and technological development are primarily the responsibility of skilled individuals.

I now emphasize what might be called "intergenerational intellectual continuity". This is based on the well-documented fact, true in every society for which I have seen information, that children of well-educated parents have a better chance of being well

\footnotetext{
${ }^{3}$ This section is based closely on Spagat (2002).
} 
educated themselves than children of poorly educated parents. I will take a particularly simple formulation that captures this idea:

$$
h_{i t}=\left\{\begin{array}{l}
\left(h_{i, t-1}\right)^{\alpha} \text { if } i \text { chooses education } \\
\underline{h} \text { otherwise }
\end{array}\right.
$$

where $0<\alpha<1$. The notion is that the better is the education of the parents the easier it will be for children to invest in human capital. There can be a variety of reasons for this that are difficult to disentangle empirically from each other. Parents with a lot of education generally have more money to invest in their children than those who do not, although this may often not be the case in transition economies. Also parents with a lot of education tend to value education more than parents who have not and also the former group knows better how to transfer education to children than the latter group. Those who do not make a special investment just get the basic level of education that is prevalent in the society.

The income of individual $i$ of generation $t$ is:

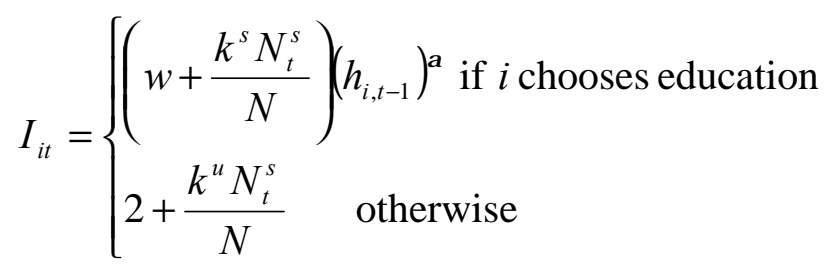

Individual $i$ of generation $t$ will chose education, i.e., to invest in human capital, if and only if 


$$
h_{i, t-1} \geq\left(\frac{2+\frac{k^{u} N_{t}^{s}}{N}}{w+\frac{k^{s} N_{t}^{s}}{N}}\right)^{\frac{1}{\alpha}} \equiv h_{t}^{c}
$$

that is, a child's human capital investment decision will depend on whether or not parental human is above a "cut-off" level that depends on the relative wages of skilled and unskilled workers and the parameter $\alpha$. Note that the cut-off level of parental human capital, $h_{t}^{c}$, is decreasing in the fraction of skilled workers. Suppose that $\underline{h}<\left(\frac{2+\frac{k^{u} N_{t}^{s}}{N}}{w+\frac{k^{s} N_{t}^{s}}{N}}\right)^{\frac{1}{\alpha}}<1$ for all $t$. This assumption can be cast in terms of parameters rather than the endogenous variables by assuming $\underline{h}<\left(\frac{2+k^{u}}{w+k^{s}}\right)^{\frac{1}{\alpha}}<\left(\frac{2}{w}\right)^{\frac{1}{\alpha}}<1$. The content of this assumption is that children of parents with basic education will always choose basic education because even with the maximum possible skill premium their family background is too weak to make it worthwhile to invest. At the same time, children of parents with one unit of human capital will always choose to invest in human capital because their family background is so good that they will invest even with the worst possible skill premium.

It is easy to show that this system will converge to a point where each dynasty will have either basic education, $\underline{h}$, or one unit of human capital. I assume that $h_{i, 0} \leq 1$ so that skilled dynasties converge from below to the human capital level of one. Any young 
individual at time $t-1$ whose parents have human capital less than $\left(\frac{2+\frac{k^{u} N_{t}^{s}}{N}}{w+\frac{k^{s} N_{t}^{s}}{N}}\right)^{\frac{1}{\alpha}}$ will choose basic education and all his descendents will remain trapped in basic education. This irreversibility of the failure of one member of a dynasty to invest in human capital is a consequence of that strong assumption, $\underline{h}<\left(\frac{2+k^{u}}{w+k^{s}}\right)^{\frac{1}{\alpha}}$, but I can relax this assumption. The corresponding result will then be that once one member of a dynasty fails to invest in human capital then his descendents will have to pay a heavy price to reverse their fortunes. In the current set-up period 1 is the only one in which a dynasty can jump down to $\underline{h}$ because wages cannot go down and any individual who invests in human capital will have at least as much as his parent. But in the crucial period 1 there is a definite possibility of loss of human capital.

An important property of this model is that there can be multiple equilibria, some with low investment rates and some with high investment rates. Consider the following illustrative example. At time zero there are three groups labeled "High", "Medium" and "Low". Each individual in the high group has parental human capital of 1, while those in the Medium and Low groups have parental human capital of $2 / 3$ and $1 / 3$ respectively. The groups are sizes 20, 60 and 20 respectively. The table summarizes the situation.

HC Distribution for a Typical Transition Economy

\begin{tabular}{|l|l|l|l|}
\hline & High & Medium & Low \\
\hline Number & 20 & 60 & 20 \\
\hline Human Capital & 1 & $2 / 3$ & $1 / 3$ \\
\hline
\end{tabular}


This distribution is meant to reflect the idea that in a typical transition economy there are a large number of people who have attained a good educational standard. I contrast the transition economy human capital distribution with that of a non-transition economy at a similar standard of living. The latter stochastically dominates the former. Note that the example works even if the Medium group is merged with the Low group.

HC Distribution for a comparable non-Transition Economy

\begin{tabular}{|l|l|l|l|}
\hline & High & Medium & Low \\
\hline Number & 20 & 30 & 50 \\
\hline Human Capital & 1 & $2 / 3$ & $1 / 3$ \\
\hline
\end{tabular}

Fix the parameter values as in the following table.

Parameter Values for the Transition and non-Transition Economies

\begin{tabular}{|l|l|l|l|}
\hline$\alpha$ & $w$ & $k^{s}$ & $k^{u}$ \\
\hline .5 & 2.3 & 1.5 & 1 \\
\hline
\end{tabular}

The transition economy has two equilibria, a good one and a bad one. In one equilibrium only the High group invests in human capital. In the other equilibrium both the High group and the Medium group invest. There is no equilibrium in which the low group invests. ${ }^{4}$ On the other hand, there is only one equilibrium in the non-transition

${ }^{4}$ When only the High group invests I have $h^{c}=\left(\frac{2.2}{2.6}\right)^{2}=.72$ so only the High group will want to invest. When both high and medium groups invest then $h^{c}=\left(\frac{2.8}{3.5}\right)^{2}=.64$ both of these groups but not the low group will want to invest. If all three groups invest then $h^{c}=\left(\frac{3}{3.8}\right)^{2}=.62$ so investment by the low group will not be sustainable. 
economy. In this equilibrium only the High group invests. ${ }^{5}$ It is clear that this example has a fair degree of robustness. Thus, I can conclude that there is much at stake in the transition economy case. If expectations can be coordinated on a positive vision of the future then many people will invest in human capital and the economy will take off on an excellent trajectory. Pessimism about the future can be lethal.

An easy extension of the model makes another potentially important policy point. A temporary inability of an educational system to support large-scale human capital investment can have a large negative effect on the growth rate of the economy. Suppose the educational system cannot allow human capital investment beyond the basic level for more than $50 \%$ of the population. Then the transition economy becomes effectively equivalent to the non-transition economy and there will be a large loss of human capital. This point is important because one often encounters the view that returns to education are generally high in transition economies and therefore there is no problem with human capital accumulation. But people must have both the incentive and the opportunity to accumulate human capital if they are to do so.

Financing constraints could also be brought back into our analysis at this point. Remember that in the previous models every agent had an incentive to acquire human capital but only those who also had sufficient financial resources actually did so. Rather

${ }^{5}$ When only the High group invests I have $h^{c}=\left(\frac{2.2}{2.6}\right)^{2}=.72$ so only the High group will want to invest. When both High and Medium groups invest then $h^{c}=\left(\frac{2.5}{3.05}\right)^{2}=.67$ so investment by the Medium group will not be sustainable. If all three groups invest then $h^{c}=\left(\frac{3}{3.8}\right)^{2}=.62$ so investment by the low group will not be sustainable. 
than return to financing constraints I turn to a more careful look at the problem of reforming the educational system and how that can fit in with long-range strategy for transition economies.

\section{Educational Reform}

This section is based on Fan, Overland and Spagat (1999). The human capital accumulation equation is

$$
h_{i t}=\left(E_{t-1}+h_{i, t-1}\right)^{\alpha} e_{i t}^{1-\alpha}
$$

where $E_{t+1}$ is the quality of the educational system at time $t+1$ and $e_{i t} \in[0,1]$ is the effort that individual $i$ of generation $t$ expends on human capital accumulation.

For simplicity I set the unskilled wage equal to one in every period and drop any externality effects on this wage. The skilled wage will satisfy $w_{t}=A_{t}$ where

$$
A_{t}=A_{t-1}+k\left(\sum_{i=1}^{N} \frac{h_{i, t-1}}{N}\right)\left(A^{*}-A_{t-1}\right)
$$

and $A^{*}>A_{0}$ are fixed and $k(\cdot)$ is an increasing function. This formulation is similar to what I have used before but it uses the average human capital level rather than the number of well-educated people and it explicitly uses a catching-up framework. It also moves the externality effect over one time period; generation $t$ creates the institutions and technology that generation $t+1$ uses and on which the wages of generation $t+1$ are based. This switch allows us to avoid multiple equilibrium problems. 
The income of individual $i$ of generation $t$ is given by

$$
I_{i t}=\left\{\begin{array}{l}
\left(1-e_{i t}\right)(1+r)+w_{t} h_{i t} \text { if } e_{i t}>0 \\
2+r \quad \text { otherwise }
\end{array}\right.
$$

where $r>0$ is an interest rate. It is there because I will be considering a costly investment decision in improving the educational system and I need an interest rate for a sensible analysis. Once I have an interest rate, consistency demands that it applies to the income of individuals.

It is not hard to show that, as in our previous model, at each time $t$ there is a cutoff level of parental human capital such that individuals above this level will invest at least some effort in acquiring human capital while those below will work both periods of their lives in the unskilled sector while allocating no effort to acquiring human capital. The cut-off level of human capital is

$$
h_{t}^{c}=h\left(w_{t}, E_{t-1}\right)
$$

where $h(\cdot, \cdot)$ is decreasing in both arguments. A higher wage and/or better educational system will induce individuals from weaker family backgrounds to invest in human capital than would otherwise be the case.

Educational restructuring is a one-shot process that can be done at any time $t$ or deferred indefinitely. Restructuring raises educational quality immediately and 
permanently from $\underline{E}$ to $\bar{E}$ where $0<\underline{E}<\bar{E}$. If education is restructured in period $s$, $E_{t}=\underline{E}$ for $t<s$ and $E_{t}=\bar{E}$ for $t \geq s .^{6}$

Let $I_{i t}^{s}$ denote the pre-tax income of individual $i$ of generation $t$ when the education system is restructured in period $s$. The baseline case under which restructuring never takes place is $s=\infty$. Define $\Psi_{t}^{s} \equiv \sum_{i=1}^{N} I_{i t}^{s}-I_{i t}^{\infty} . \Psi_{t}^{s}$ is generation $t$ 's total surplus pre-tax income due to restructuring in period $s$ compared to never restructuring.

The first fact to note is that restructuring generates more pre-tax income for every generation after the restructuring occurs. The reason for this is as follows. Restructuring encourages more human capital investment than would otherwise be the case, which leads to higher incomes for those who take advantage of the better education system. This increases average human capital so wages grow faster than they would have without restructuring. The next generation has better educated parents and anticipates higher wages per unit of human capital than would have been the case without restructuring. The process continues.

I cannot conclude from this fact that immediate educational restructuring is a good investment because I have not yet considered the costs of this policy. Educational restructuring requires borrowing a fixed sum, $C$. If education is restructured at time $s$,

\footnotetext{
${ }^{6}$ World Bank (1995) and OECD (1998) both criticize the Russian education system for producing the wrong mix of specialties, i.e., primarily scientists and engineers to serve the Soviet military-industrial complex, for overemphasis on specialization and for overreliance on rote learning. One need not accept all of these points in order to agree with our general point that the education system is not suited to the needs of a modern market economy and that reform can unlock much underlying potential. Other transition economies are in a similar situation.
} 
repayment begins with the adults of generation $s+1$, i.e., the first generation that is able to take advantage of the improved educational opportunities.

I will consider two possible financing schemes for educational restructuring. Under normal financing debt is serviced in perpetuity so that each generation after $s+1$ owes $r C$. Under flexible financing at time $s=0$ generation 1 pays $\Psi_{1}^{0}$ and generation 2 pays $\left(r C-\Psi_{1}^{0}\right)(1+r)+r C$. This scheme takes advantage of the fact that generation 2 might receive enough surplus from restructuring at time 0 that it would be able to pay not only its own loan service obligations but also the portion of generation 1's obligations with interest that the latter cannot handle out of surplus. I will assume normal financing except for the last proposition of this paper.

Define $s^{*}=\min \left\{s: \Psi_{s+1}^{s} \geq r C\right\}$. Under normal financing, any generation before $s^{*}+1$ would vote unanimously against educational restructuring while generation $s^{*}+1$ would vote in its favor. Therefore, any reasonable political economy theory would imply that, under normal financing, educational restructuring would occur precisely at time $s^{*}$. The next important fact is that there are only three possible paths for the human capital of a dynasty. They are;

1. Human capital increases monotonically from time 0 . The relative wage of skilled labor and the efficiency of the education system are increasing monotonically in time. Therefore, if it is optimal for a child to surpass his parent, it must be optimal for the grandchild, facing an even better human- capital-acquisition environment, to surpass the child.:

2. Human capital decreases monotonically from time 0 . Suppose the quality of the education system is poor and wages are low so that a child is not willing to 
reproduce his parent's human capital level. If productivity increases slowly, then a dynasty may continue to run down its human capital stock.:

3. Human capital follows a U-shaped curve. This case begins like the second but, either due to a late educational restructuring or a substantial increase in the skilled wage, a child's human capital level might eventually be able to cross over that of his parent's. Once this occurs, the dynamics of the first case take over and human capital for that dynasty never again decreases.:

One could say that, implicitly or explicitly scenario 3, with its temporary neglect of education, is the policy of many transition economy governments.

Another important fact is that I can define $\bar{h}>\underline{h}>0$ with the property that if education is reformed the human capital of every dynasty will converge to either $\bar{h}$ or 0 and if education is not reformed he human capital of every dynasty will converge to either $\bar{h}$ or 0 .

Proposition 1. (Comparative steady states) Suppose that $h^{c}\left(A^{*}, \bar{E}\right)>0$. (a) If at any time t the human capital of a dynasty falls below $h^{c}\left(w_{t}, E_{t}\right)>0$, the human capital of that dynasty vanishes forever. (b) The number of dynasties whose human capital level converges to 0 is decreasing in $s .^{7}$

This proposition already contains the idea that delaying educational restructuring can be costly for the long-run future of the economy. The bad scenario is that restructuring is delayed for one generation, many individuals who have sufficient parental human capital to make it worthwhile to invest in human capital with a restructured 
educational system do not have enough parental human capital to do so with an unrestructured one. These individuals drop down to basic education and their descendents will not invest even with a restructured educational system.

Let $F_{1}$ denote the number of individuals of generation one who will choose to invest zero units of time in acquiring human capital at time zero if the education system is not restructured at time zero. I have the following result.

\section{Proposition 2. (Restructuring: now or much later) Suppose there exists $i$ such that $h_{i 0} \geq \bar{E}-\underline{E}$. Then if $F_{1}$ is sufficiently close to $N$, it is the case that $s^{*} \neq 0 \Rightarrow s^{*} \neq 1$.}

The first condition in the proposition means that the difference for some child of having a highly educated parent versus having a very poorly educated parent is at least as important to his development as is the difference between having a reformed education system versus having an unreformed system. The condition on $F_{1}$ is far from necessary for the result. The intuition of proposition 2 is as follows. If restructuring is not implemented in period zero, the present generation of young people will invest lightly in education. This will diminish their ability to facilitate their children's human capital development and retard the rate of the economy's productivity growth, further eroding their children's incentive to invest in education. Hence, an educational restructuring initiative in period one does not yield enough surplus to allow these children to pay for its cost. Therefore, if restructuring is not implemented in period zero, it is delayed for at least another generation.

The next two propositions indicate that $s^{*}$ has some nice properties.

\footnotetext{
${ }^{7}$ All the propositions are proven in Fan, Overland and Spagat (1999).
} 
Proposition 3. ( $s^{*}$ is an optimal restructuring time) If $e \leq h_{i 0} \leq \bar{e}, \forall i$ and $h^{c}\left(w_{0}, \underline{E}\right)<0$, $s^{*}$ is Pareto Optimal and Pareto dominates any $s>s^{*}$.

The conditions imply that the human capital of each dynasty will be nonincreasing in time without restructuring and nondecreasing in time with restructuring, i.e., I eliminate the U-shape scenario.

Proposition 4. (Restructuring is egalitarian) Suppose that the conditions of Proposition 3 hold. Then the economy under $s^{*}$ has a lower Gini coefficient for every time after $s^{*}$ than the economy would have for any $s>s^{*}$.

So educational restructuring at time $s^{*}$ is efficient and egalitarian. But I must be careful not to jump too quickly to the conclusion that this is the best policy. Recall that Proposition 2 suggests that it is quite possible that $s^{*}=2$. However, time 2 does not Pareto dominate time 0 . In fact, by I know that all generations after and including generation 3 prefer time 0 to time 2. Moreover, it is quite possible that generation 2 prefers time 0 and that generation 1 is close to being on a margin of indifference. In this plausible case, delaying restructuring would give a small advantage to generation 1 while punishing all future generations, perhaps severely. Therefore, while $s^{*}$ is a Pareto Optimal choice, it might be undesirable from a broader welfare point of view. Second, the next proposition shows that expanding the range of financing mechanisms can actually make time 0 Pareto superior to time 2 . 
Proposition 7. (Flexible financing argues for early restructuring) Suppose $s^{*}=2$. Restructuring at time 0 using the flexible financing scheme creates a Pareto improvement over restructuring at time 2 under the standard financing scheme if and only if $r C(1+r)+r C \leq \Psi_{1}^{0}(1+r)+\Psi_{2}^{0}$.

Moving too fast toward full cost recovery of an educational reform can be counterproductive. Generation 1 might reject a proposal to restructure education if its members would have to pay their full share of the cost, $r C$. However, if a loan is offered on sufficiently soft terms to this generation, they will accept the arrangement and many members will alter their behavior by investing more of their own time in human capital acquisition. Generation 2, now endowed with higher quality parents as a result of the early reform, will happily make up for the initial softness of the loan.

\section{Conclusion}

What makes transition economies special? Of course, one could point to lots of things. But a crucial one, if not the crucial one is that they have, or at least they had, high human capital relative to their living standards. The New Growth Theory emphasizes human capital quite a bit and there is significant empirical support for the intuitively very plausible idea that human capital is very important for growth. So transition economies could have great prospects as argued, for example, in Barry (2002). ${ }^{8}$ Unfortunately, I do not think things are quite that simple. I do believe there is the potential for very rapid growth in transition economies so that living standards rise to meet human capital levels. But I also believe there is potential for substantial human capital decline so that human

\footnotetext{
${ }^{8}$ This analysis is predicated on EU accession.
} 
capital levels fall to meet living standards. In fact, I believe that both phenomena are happening right now although they can be reversed.

Educational standards and traditions are built up slowly over long period of time. Although educational standards take a long time to develop, they can be lost relatively quickly. I think that the best way to illustrate this is to focus on families. Families are a major transmission belt for education. Well-educated parents tend to produce welleducated children. A society with a lot of well-educated parents is in an excellent position to pass this education down to it younger generation. However, if something comes along and disrupts this intergenerational transfer then a society can be set back for decades.

Such disruption can result, for example, from a major economics crisis that decreases the economic returns to acquiring education, a big structural shift in the economy that makes parts of the education system obsolete, deterioration in the quality of the education system, e.g., due to funding cuts or an increase in the cost of acquiring education that restricts access to the education system. ${ }^{9}$ The key point is that that these disruptions are bad not just for the current generation of young people, but also that damage done to the current generation of young people is likely to reverberate for several generations as poorly educated young people turn into poorly prepared parents. Thus, several generations of work can be squandered very quickly.

Is human capital deterioration a serious phenomenon in transition economies? I think it is in some and it isn't in others. Generally speaking the countries that have been doing well, and are first in line to join the EU, seem to be doing a good job of preserving

\footnotetext{
${ }^{9}$ I can think of other mechanisms. For example, it takes a long time and a lot of effort to create a large number of good teachers. Yet they might disperse rather quickly if they are poorly treated for too long.
} 
and even enhancing their human capital. To get a sense of the situation, consider preschool enrollment. This is an important indicator because it is well established that good pre-schools have positive long-lasting effects for children yet pre-school is not mandatory. Between 1989 and 1999 pre-school enrollment has held steady in Central Europe but has plummeted in the Caucasus and Central Asia. Other indicators, like public spending on education and secondary school enrollments tell a similar story. A bright spot is enrollment in higher education although the quality of such education is doubtful. ${ }^{10}$

It is important to realize also that looking at the national level can be quite misleading. There are, for example, big urban-rural differences. In many countries educational standards in the capital city are far above those elsewhere in the country. The point is that it is likely that throughout the post-communist world there are pockets of poverty forming that could prove to be quite intractable. Human capital deterioration seems very real for some transition countries and even many regions within otherwise successful countries.

Should transition economies make a priority of investing in education? To many people the answer has been "obviously no". Their reasoning is human capital is a bright spot in the transition economy landscape. Invoking the standard concept of diminishing marginal returns one would want to invest a lot in backward areas where marginal products are high rather than successful areas where they are low. I would challenge this common response. In my view relatively modest investments now might prevent very large future costs

${ }^{10}$ This data can be found on http://www.unicef-icdc.org/documentation/index.html. 


\section{BIBLIOGRAPHY}

Aghion, Philippe and Peter Howitt, Endogenous Growth Theory, MIT, Cambridge MA, 1998.

Alexeev, Michael and Michael Kaganovich, "Returns to Human Capital Under Uncertain Reform: Good Guys Finish Last," Journal of Economic Behavior and Organization 37, 1:53-70, September 1998.

Banerjee, Abhijit and Andrew Newman, "Risk-Bearing and the Theory of Income Distribution", Review of Economic Studies, 58, 211-235, 1991.

Barro, Robert and Xavier Sala-i-Martin, Economic Growth, McGraw-Hill, New York, 1995.

Benabou, Roland, "Inequality and Growth", in B. Bernanke and J. Rotemberg (eds.) NBER Macroeconomics Annual, MIT Press, Cambridge MA, 1996.

Barry, Frank, "EU Accession and FDI Flows to CEE Countries: Lessons from the Irish Experience," unpublished manuscript, University College Dublin, 2002.

Deininger K. and L. Squire, "New Ways of Looking at Old Issues: Inequality and Growth," Journal of Development Economics, 57, 259-87, 1998.

Drazen, Allan, Political Economy in Macroeconomics, Princeton, Princeton, 2000.

European Bank for Reconstruction and Development, Transition Report 2000, EBRD, 2000.

Fan, Chengze Simon, Jody Overland and Michael Spagat, "Human Capital, Growth and Inequality in Russia", Journal of Comparative Economics, 27, 618-643, 1999.

Galor, Oded and Joseph Zeira, "Income Distribution and Macroeconomics", Review of Economic Studies, 60, 35-52, 1993.

Gros, Daniel and Marc Suhrcke, "Ten Years After: What is Special About Transition Countries,” CESifo working paper number 327, 2000.

Krueger, Alan and Mikael Lindahl, "Education for Growth: Why and For Whom?, Journal of Economic Literature, 39, 1101-1136, December 2001.

Micklewright, John, "Education, Inequality and Transition”, Economics of Transition, 7, 343-376, 1999. 
OECD, Review of National Policies for Education: Russian Federation, OECD, Paris, 1998.

Perotti, Roberto, "Political Equilibrium, Income Distribution, and Growth", Review of Economic Studies, 60, 755-76, 1993.

Spagat, M. "Human Capital and the Future of Transition Economies", unpublished manuscript, http://www2.rhbnc.ac.uk/ uhte014/Research.htm, 2002.

World Bank, Russia: Education in the Transition. World Bank, Washington DC, 1995.

Münich, Daniel, Jan Svejnar and Katherine Terrell, "Returns to Human Capital Under the Communist Wage Grid and During the Transition to a Market Economy", CEPR working paper number 2332, 1999.

UNICEF, Young People in Changing Societies, UNICEF, 2000.

UNICEF, A Decade of Transition, UNICEF, 2001. 


\section{DAVIDSON INSTITUTE WORKING PAPER SERIES - Most Recent Papers}

The entire Working Paper Series may be downloaded free of charge at: www.wdi.bus.umich.edu

CURRENT AS OF 9/23/02

\begin{tabular}{|c|c|c|}
\hline Publication & Authors & Date \\
\hline $\begin{array}{l}\text { No. 499: Human Capital, Growth and Inequality in Transition } \\
\text { Economies }\end{array}$ & Michael Spagat & July 2002 \\
\hline No. 498: Understanding Czech Long-Term Unemployment & $\begin{array}{l}\text { Štěpán Jurajda and Daniel } \\
\text { Münich }\end{array}$ & Aug. 2002 \\
\hline $\begin{array}{l}\text { No. 497: Rent Seeking and Government Ownership of Firms: An } \\
\text { Application to China's Township-Village Enterprises }\end{array}$ & Jiahua Che & Sep. 2002 \\
\hline No. 496: Labor Market Flexibility in Central and East Europe & Jan Svejnar & Aug. 2002 \\
\hline $\begin{array}{l}\text { No. 495: When Information Dominates Comparison: A Panel Data } \\
\text { Analysis Using Russian Subjective Data }\end{array}$ & Claudia Senik & May 2002 \\
\hline No. 494: Corruption and Cross-Border Investment: Firm Level Evidence & $\begin{array}{l}\text { Beata K. Smarzynska and Shang- } \\
\text { Jin Wei }\end{array}$ & Aug. 2002 \\
\hline $\begin{array}{l}\text { No. 493: Modeling Sequences of Long Memory Positive Weakly } \\
\text { Stationary Random Variables }\end{array}$ & Dmitri Koulikov & Aug. 2002 \\
\hline $\begin{array}{l}\text { No. 492: Effects of Ownership and Financial Status on Corporate } \\
\text { Environmental Performance }\end{array}$ & $\begin{array}{l}\text { Dietrich Earnhart and Lubomír } \\
\text { Lízal }\end{array}$ & Aug. 2002 \\
\hline $\begin{array}{l}\text { No. 491: Does Economic Uncertainty Have an Impact on Decisions to } \\
\text { Bear Children? Evidence from Eastern Germany }\end{array}$ & $\begin{array}{l}\text { Sumon Kumar Bhaumik and } \\
\text { Jeffrey B. Nugent }\end{array}$ & July 2002 \\
\hline $\begin{array}{l}\text { No. 490: The Reallocation of Workers and Jobs in Russian Industry: } \\
\text { New Evidence on Measures and Determinants }\end{array}$ & J. David Brown and John S. Earle & Aug. 2002 \\
\hline $\begin{array}{l}\text { No. 489: The Incidence and Cost of Job Loss in a Transition Economy: } \\
\text { Displaced Workers in Estonia, 1989-1999 }\end{array}$ & $\begin{array}{l}\text { Hartmut Lehmann, Kaia Phillips } \\
\text { and Jonathan Wadsworth }\end{array}$ & Aug. 2002 \\
\hline No. 488: Integration: An Empirical Assessment of Russia & $\begin{array}{l}\text { Daniel Berkowitz and David N. } \\
\text { DeJong }\end{array}$ & Feb. 2002 \\
\hline $\begin{array}{l}\text { No. 487: Dual Inflation under the Currency Board: The challenges of } \\
\text { Bulgarian EU accession }\end{array}$ & $\begin{array}{l}\text { Nikolay Nenovsky and Kalina } \\
\text { Dimitrova }\end{array}$ & July 2002 \\
\hline $\begin{array}{l}\text { No. 486: Worker Flows, Job Flows and Firm Wage Policies: } \\
\text { An Analysis of Slovenia }\end{array}$ & $\begin{array}{l}\text { John Haltiwanger and Milan } \\
\text { Vodopivec }\end{array}$ & July 2002 \\
\hline $\begin{array}{l}\text { No. 485: Do Schumpeterian Waves of Creative Destruction Lead to } \\
\text { Higher Productivity? Panel Data Evidence from Poland }\end{array}$ & Frederic Warzynski & July 2002 \\
\hline $\begin{array}{l}\text { No. 484: Labor Market Institutions and Restructuring: Evidence from } \\
\text { Regulated and Unregulated Labor Markets in Brazil }\end{array}$ & Jasper Hoek & July 2002 \\
\hline $\begin{array}{l}\text { No. 483: The Balassa-Samuelson effect in Central and Eastern Europe: } \\
\text { Myth or reality? }\end{array}$ & $\begin{array}{l}\text { Balázs Égert, Imed Drine, Kirsten } \\
\text { Lommatzsch and Christophe } \\
\text { Rault }\end{array}$ & July 2002 \\
\hline No. 482: Real Exchange Rates in Transiti & Boštjan Jazbec & July 2002 \\
\hline $\begin{array}{l}\text { No. 481: Labor Force Participation Dynamics in the Romanian Labor } \\
\text { Market }\end{array}$ & Alexandru Voicu & July 2002 \\
\hline $\begin{array}{l}\text { No. 480: Equilibrium Real Exchange Rates in Central Europe's } \\
\text { Transition Economies: Knocking on Heaven's Door }\end{array}$ & Balázs Égert & July 2002 \\
\hline $\begin{array}{l}\text { No. 479: The Impact of Minimum Wages on Wage Inequality and } \\
\text { Employment in the Formal and Informal Sector in Costa Rica }\end{array}$ & $\begin{array}{l}\text { Fatma El-Hamidi and Katherine } \\
\text { Terrell }\end{array}$ & Apr. 2001 \\
\hline $\begin{array}{l}\text { No. 478: Beyond Oaxaca -Blinder: Accounting for Differences in } \\
\text { Household Income Distributions }\end{array}$ & $\begin{array}{l}\text { François Bourguignon, Francisco } \\
\text { H. G. Ferreira and Phillippe G. } \\
\text { Leite }\end{array}$ & Feb. 2002 \\
\hline $\begin{array}{l}\text { No. 477: Participation Behavior of East German Women after German } \\
\text { Unification }\end{array}$ & Holger Bonin and Rob Euwals & July 2002 \\
\hline No. 476: Duration and Risk of Unemployment in Argentina & $\begin{array}{l}\text { Sebastian Galiani and Hugo A. } \\
\text { Hopenhayn }\end{array}$ & Oct. 2001 \\
\hline $\begin{array}{l}\text { No. 475: After, Before and During: Returns to Education in the } \\
\text { Hungarian Transition }\end{array}$ & $\begin{array}{l}\text { Nauro F. Campos and Dean } \\
\text { Jolliffe }\end{array}$ & Apr. 2002 \\
\hline No. 474: The Locking-in Effect of Subsidized Jobs & Jan C. van Ours & June 2002 \\
\hline
\end{tabular}

